\title{
Suramin inhibits the growth of nasopharyngeal carcinoma cells via the downregulation of osteopontin
}

\author{
SHAN JIANG ${ }^{1 *}$, XIAOPIN CHEN ${ }^{1 *}$, CHUNYAN LI $^{2}$, XINGPING ZHANG ${ }^{1}$, \\ TAO ZHANG ${ }^{1}$, YUJUAN YUE ${ }^{1}$ and GUANG YANG ${ }^{3 *}$
}

\begin{abstract}
Departments of ${ }^{1}$ Oncology and ${ }^{2}$ Endocrine and Breast Surgery, The First Affiliated Hospital, Chongqing Medical University, Chongqing 400016; ${ }^{3}$ State Key Laboratory of Oncology in South China, Department of Imaging and Interventional Radiology, Cancer Center, Sun Yat-sen University, Guangzhou, Guangdong 510060, P.R. China
\end{abstract}

Received April 20, 2012; Accepted August 28, 2012

DOI: $10.3892 / \mathrm{mmr} .2012 .1074$

\begin{abstract}
Radiotherapy is the principal therapy for nasopharyngeal carcinoma (NPC) at early stages. A number of chemotherapeutic methods have been used to inhibit the progression of NPC at elevated stages. Suramin has been reported to inhibit the growth of certain tumor cells via various pathways. In the present study, we aimed to analyze the effects of suramin on the proliferation of NPC cells (CNE-2). Suramin was proved to demonstrate NPC cell growth-inhibiting effects both in a dose- and time-dependent manner. To determine the potential mechanisms of these effects, western blotting and flow cytometric analysis were performed. Suramin was found to have the potential to induce cell cycle arrest in S-phase CNE-2 cells. Additionally, we found that the OPN level may decrease in suramin-treated CNE-2 cells. The changes of certain apoptosis- and p-AKT-associated proteins possibly regulating the OPN expression were measured by western blotting. In conclusion, suramin may function as a potential agent for the adjunctive therapy of NPC.
\end{abstract}

\section{Introduction}

Nasopharyngeal carcinoma (NPC) is a common malignant tumor in southern China and Southeast Asia (1,2). Suramin is a naphthalene trisulfonic acid derivative originally used as an agent for treating trypanosomiasis and onchocerciasis (3). Previous studies suggested that suramin inhibits the growth of various tumor models $(4,5)$. Suramin may interact with cell enzymes, such as DNA polymerase, topoisomerase II

Correspondence to: Dr Guang Yang, 651 Dongfeng Rd East, State Key Laboratory of Oncology in South China, Department of Imaging and Interventional Radiology, Cancer Center, Sun Yat-sen University, Guangzhou 510060, P.R. China

E-mail: yangguang@sysucc.org.cn

${ }^{*}$ Contributed equally

Key words: suramin, nasopharyngeal carcinoma, osteopontin, growth and protein kinase $\mathrm{C}$ to inhibit tumor growth, and has been tested in clinical trials (6). Osteopontin (OPN) is a secreted arginine-glycine-asparic acid (RGD)-containing phosphoprotein which contains a predicted thrombin cleavage site. By binding to several integrins and CD44 variants, OPN plays a crucial role in tumorigenesis, tumor invasion, tumor angiogenesis and metastasis in several types of cancer (7-11). Findings of previous studies have also demonstrated that OPN may promote cell survival through the inhibition of apoptosis (12). A recent report has proven that OPN has the potential to regulate the growth and migration of NPC cells (13). Radiotherapy is the principal treatment for patients with early-stage NPC. High pre-treatment plasma osteopontin level in NPC patients has been demonstrated to be a significant predictor of poor response to radiotherapy $(14,15)$. The effect of suramin on the OPN expression in NPC cells, however, has yet to be reported.

Suramin has as yet not been studied in the framework of NPC. Therefore, we used a poorly-differentiated NPC cell line (CNE-2) to investigate the effects of suramin on proliferation, apoptosis, cell cycle arrest and the changes of various related proteins in NPC cells.

\section{Materials and methods}

Materials. Antibody against OPN was purchased from Sigma (St. Louis, MO, USA), against $\beta$-actin from PTG (Chicago, IL, USA), while other antibodies used in this investigation were purchased from Santa Cruz Biotechnology, Inc. (Santa Cruz, CA, USA). Suramin was purchased from Alexis (Lausen, Switzerland).

Cell culture. The cell line CNE-2 (a gift from Dr Kewei Wu, State Key Laboratory of Oncology in Southern China, SunYat-Sen University, Guangzhou, China) was cultured in DMEM, supplemented with heat-inactivated fetal calf serum supplemented with penicillin $(100 \mathrm{U} / \mathrm{ml})$ and streptomycin $(100 \mathrm{mg} / \mathrm{ml})$ in $5 \% \mathrm{CO}_{2}$ at $37^{\circ} \mathrm{C}$.

MTT assay. The effects of a sustained application of suramin on the viability of CNE-2 cells were determined by MTT assay. The cells were seeded in 96-well plates at a concentration of 5,000 cells/well in a volume of $150 \mu$ l of cell culture 
medium per well. After $24 \mathrm{~h}$, suramin was added at different concentrations $(50,100$ and $200 \mu \mathrm{M})$ to the wells in triplicate. The plates were incubated at $37^{\circ} \mathrm{C}$ with $5 \% \mathrm{CO}_{2}$ for $48 \mathrm{~h}$, and cells were then additionally treated with suramin $(100 \mu \mathrm{M})$ and cultured for 24,48 and $72 \mathrm{~h}$. A $20 \mu 1$ sample of MTT solution $(5 \mathrm{~g} / 1$, dissolved in PBS) was added to each well, and the plates were incubated at $37^{\circ} \mathrm{C}$ for an additional $4 \mathrm{~h}$. The supernatant was discarded, then $150 \mu 1$ dimethylsulfoxide was added to dissolve the insoluble MTT formazan. The absorbance values at $570 \mathrm{~nm}$ (A570) were determined by a multi-well plate reader (Tecan, Maennedorf, Switzerland).

Flow cytometric analysis. Cells were cultured with suramin $(100 \mu \mathrm{M})$ for 24 or $48 \mathrm{~h}$. Apoptosis and the cell cycle were determined by cytofluorimetry. To detect apoptotic cells, labeling tests involving both propidium iodide (PI) and annexin-V were conducted using an Annexin-V staining kit (Invitrogen, Shanghai, China), according to the manufacturer's instructions. Briefly, at least $1 \times 10^{6}$ cells were harvested by trypsinization, incubated with FITC-labeled annexin-V and PI stock solutions for $10 \mathrm{~min}$ at room temperature and analyzed using a flow cytometer (Beckman Counter, Miami, FL, USA). For analysis of the cell cycle, cells treated in different ways were subjected to flow cytometric analysis for chromosomal DNA. DNA labeling was performed using the Cycle TEST TM PLUS DNA reagent kit (BD Biosciences Pharmingen, San Diego, CA, USA). Briefly, the cells were washed 3 times with PBS, then mixed with $250 \mu \mathrm{l}$ of solution A, incubated for $10 \mathrm{~min}$ at $25^{\circ} \mathrm{C}$, and subsequently mixed with $200 \mu \mathrm{l}$ of solution B for $10 \mathrm{~min}$ at $25^{\circ} \mathrm{C}$. Solution C $(200 \mu \mathrm{l})$ was added into each reaction, followed by a 10 min incubation in the dark on ice. The samples were then analyzed using a flow cytometer (Beckman Counter).

Western blot analysis. Cells were cultured with suramin $(100 \mu \mathrm{M})$ for 24,48 and $72 \mathrm{~h}$, then harvested and lysed for total protein extraction. Protein concentration was determined using a Bio-Rad protein assay kit (Bio-Rad, China). Equal amounts of protein were separated by $12 \%$ SDS-PAGE and transferred onto PVDF membranes. The membranes were rinsed with Tris-buffered saline and Tween (TBST, Probe Co. Ltd., China) and incubated in blocking buffer (5\% dried milk in PBS) for $1 \mathrm{~h}$ at $37^{\circ} \mathrm{C}$, followed by incubation with primary antibodies at $4^{\circ} \mathrm{C}$ overnight. The polyclonal antibody against OPN was used at a 1000-fold dilution. Monoclonal antibody against $\beta$-actin was used at a 2000 -fold dilution. After three washes with TBST, the membranes were incubated with their corresponding secondary antibodies for $1 \mathrm{~h}$. The blots were visualized by an enhanced chemiluminescence detection system (Invitrogen). The expression of $\beta$-actin was used as an optimization regulator for protein loading.

Statistical analysis. Statistical analysis was performed using the unpaired Student's t-test. $\mathrm{P}<0.05$ was considered to indicate a statistically significant difference.

\section{Results}

Effects of suramin on the proliferation of NPC CNE-2 cells. Cells were cultured at a low cell density of $\sim 5,000$ cells/well.
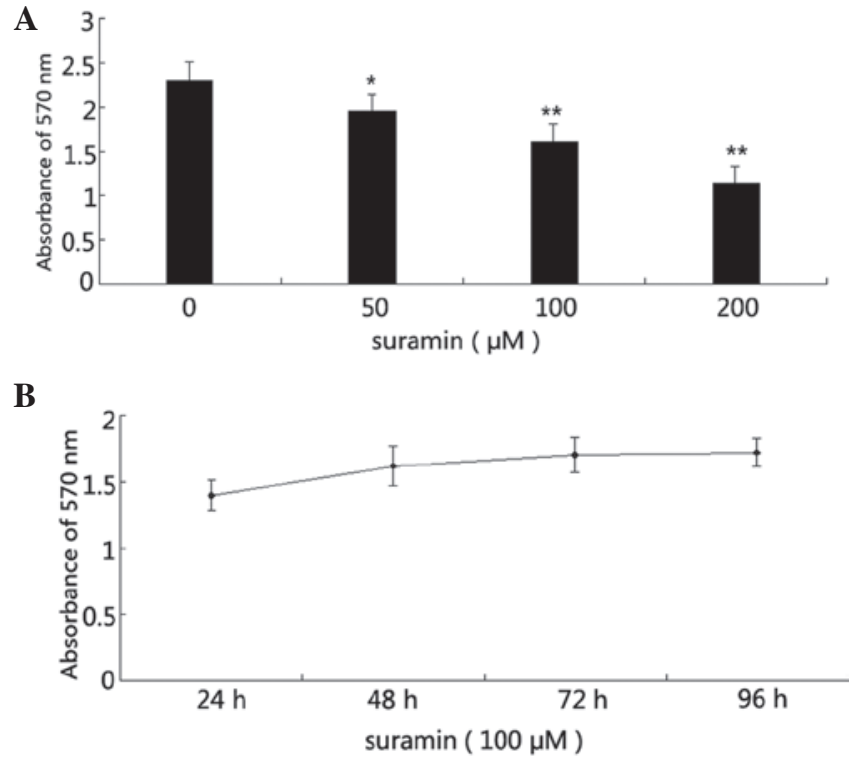

Figure 1. Effect of suramin on the growth of nasopharyngeal carcinoma cell lines. (A) Dose-dependent effect of the suramin on CNE-2 cell growth, after 48-h incubation. (B) Time-dependent effect of suramin $(100 \mu \mathrm{M})$ on CNE-2 cell growth, after 24-, 48-, 72- and 96-h incubation. Significance between control and treated conditions: ${ }^{*} \mathrm{p}<0.05,{ }^{* *} \mathrm{p}<0.001$.

Cell viability was measured by MTT assay following suramin treatment. The results showed that CNE-2 cell growth was inhibited by suramin treatment in a dose- and time-dependent manner, with a marked effect after $48 \mathrm{~h}$ (Fig. 1A and B).

Effects of suramin on the cell cycle. Cell cycle analysis was carried out to investigate whether the growth inhibitory effect of suramin on NPC cells was induced by cell cycle arrest. Following sustained incubation of the cells with suramin for $24 \mathrm{~h}$, the proportion of CNE-2 cells in the S phase of the cell cycle was found to have significantly increased when exposed to suramin (Fig. 2). This finding indicated that S-phase arrest was involved in the growth inhibitory effect on CNE-2 cells. The concentration of suramin used was $100 \mu \mathrm{mol} / \mathrm{l}$.

Determination of apoptosis by flow cytometric analysis. Subsequent to 48-h incubation with suramin, flow cytometric analysis with propidium iodide (PI) and annexin-V staining was performed. A clear increase in the annexin V-positive and PI-positive cell fractions was observed (Fig. 3A), indicating that suramin may induce apoptosis in NPC cells. The level of some genes was also found to be associated with CNE-2 cell apoptosis (bcl-2, bax and caspase 3). Subsequent to suramin treatment, the level of bcl-2 decreased while that of bax increased, and caspase 3 also showed a cleaved band (Fig. 3B). Thus, at a concentration of $100 \mu \mathrm{mol} / \mathrm{l}$ suramin may induce apoptosis in NPC cells.

Suramin decreased OPN expression in NPC cells. Downregulation of the OPN level in NPC cells may increase the sensitivity of NPC to radiotherapy, thus the OPN level of NPC cells when treated with suramin was measured. To determine the change in OPN expression following culture with suramin, the cells were incubated in medium with or without suramin content for 24,48 and $72 \mathrm{~h}$. Western blotting showed an obvious 


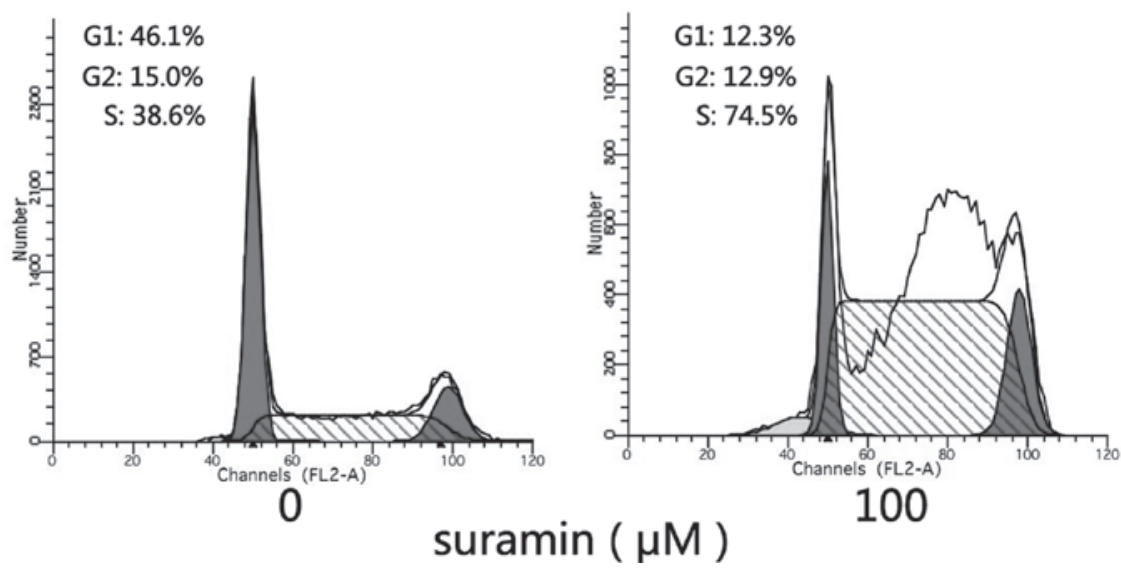

Figure 2. Flow cytometric analysis for the cell cycle: the proportion of S-phase significantly increased when NPC cells were treated with suramin (100 $\mu \mathrm{M})$ for $24 \mathrm{~h}$.

\section{A}

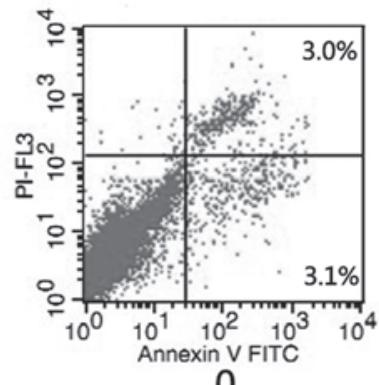

$\operatorname{suramin}(\mu \mathrm{M})$

B
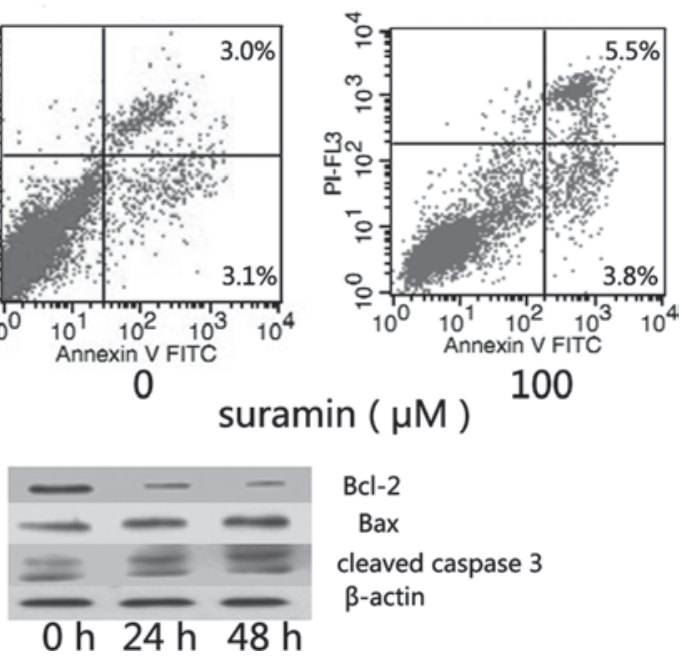

Figure 3. Suramin-induced apoptosis of NPC cells. (A) Flow cytometric analysis for apoptosis of NPC cells treated with suramin $(100 \mu \mathrm{M})$ for $48 \mathrm{~h}$. (B) The level of Bax was elevated while Bcl-2 decreased in suramin-treated NPC cells. The cleaved band of caspase 3 indicated apoptosis occurred in suramin-treated NPC cells.

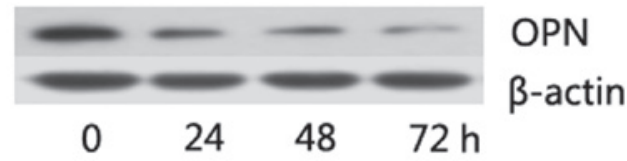

Figure 4. Effect of suramin on the level of OPN in NPC cells. The level of OPN decreased in suramin-treated NPC cells at the indicated time. Western blot analyses were performed three times.

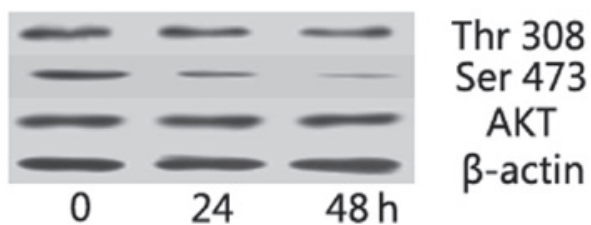

Figure 5.Effect of suramin on the level of p-AKT in NPC cells. Western blotting results showed that the quantity of p-Akt (Thr308, Ser473) was reduced in suramin-treated NPC cells. Western blotting was performed three times. decrease of OPN protein in CNE-2 cells, with the optimization of equal protein loading regulated by $\beta$-actin (Fig. 4). Suramin was used at a concentration of $100 \mu \mathrm{M}$.

Akt pathway is involved in the growth inhibitory effect of suramin on NPC cells. OPN expression is reportedly regulated by the Akt pathway in several tumor models. In the present study, the effect of suramin on Akt pathway in NPC cells was investigated by western blotting. Akt phosphorylation at Thr 308 and Ser 473 was reduced in suramin-treated NPC cells (Fig. 5). These results suggest that suramin may decrease the p-Akt expression in NPC cells.

\section{Discussion}

Suramin is known to inhibit cancer cell growth in several models through a number of mechanisms (4-6). The present study aimed to investigate the effects of suramin on NPC cell growth as well as on the potential mechanisms. Our results showed that suramin reduced cell viability in a time- and dose-dependent manner. Similar to other studies, we found that suramin-induced cell cycle arrest in the $\mathrm{S}$ phase may be detected in NPC cells, the reason of which has yet to be determined. This finding may be associated with the inhibitory effects of various cell cycle-related proteins (16). Some chemotherapeutic drugs show more cytotoxicity to the cells arrested in $S$ phase $(17,18)$, therefore suramin-induced recruitment of cancer cells to the $\mathrm{S}$ phase may sensitise poorly-differentiated NPC cells to those drugs. Clinically, the poorly-differentiated models are more common than the well-differentiated ones, thus, in this investigation the poorly-differentiated CNE-2 cell line was used. Suramin-induced apoptosis was also demonstrated by flow cytometry, whereas changes in bcl-2, bax and caspase 3 were detected by western blotting.

A recent study also showed that OPN might regulate NPC cell growth (13). The present investigation demonstrates for the first time that suramin inhibits NPC cell growth via the downregulation of OPN. Higher OPN levels were detected in NPC patient serum, also proving that a higher OPN level decreased the sensitivity of radiotherapy to NPC, provided that radiotherapy is the principal therapy for NPC. Suramin-induced 
downregulation of OPN in NPC cells may sensitise poorlydifferentiated NPC cells to radiotherapy. The role of AKT pathway to cell proliferation was thoroughly studied in a number of tumor models, and certain recent reports have demonstrated that OPN levels may be regulated by the AKT pathway in several tumor cells $(19,20)$. We hypothesized that this might also be the case for NPC cells, and investiged the effect of suramin on AKT pathway in NPC cells. OPN is a secreted protein, often playing an extracellular role by binding to certain membrane receptors, given that suramin may interact with various growth and angiogenic factors. To determine whether suramin is able to directly interact with OPN, additional studies are required.

In conclusion, our data have shown that suramin has a growth inhibitory effect and induces cell cycle arrest in NPC cells. Given that additional related mechanisms are currently being investigated, we believe that suramin is a promising alternative for the adjunctive therapy of NPC.

\section{Acknowledgements}

The authors are grateful to Dr Kong at the Department of Inspection of the First Affiliated Hospital at the Sun Yat-sen University for his skillful assistance with our flow cytometric analysis.

\section{References}

1. Chang ET and Adami HO: The enigmatic epidemiology of nasopharyngeal carcinoma. Cancer Epidemiol Biomarkers Prev 15: 1765-1777, 2006

2. Guigay J: Advances in nasopharyngeal carcinoma. Curr Opin Oncol 20: 264-269, 2008.

3. Hawking F: Suramin: with special reference to onchocerciasis. Adv Pharmacol Chemother 15: 289-322, 1978.

4. Song S, Yu B, Wei Y, Wientjes MG and Au JL: Low-dose suramin enhanced paclitaxel activity in chemotherapy-naive and paclitaxel-pretreated human breast xenograft tumors. Clin Cancer Res 10: 6058-6065, 2004.

5. Bhargava S, Hotz B, Hines OJ, Reber HA, Buhr HJ and Hotz HG: Suramin inhibits not only tumor growth and metastasis but also angiogenesis in experimental pancreatic cancer. J Gastrointest Surg 11: 171-178, 2007.

6. Vogelzang NJ, Karrison T, Stadler WM, Garcia J, Cohn H, Kugler J, et al: A phase II trial of suramin monthly x 3 for hormone-refractory prostate carcinoma. Cancer 100: 65-71, 2004.
7. Agrawal D, Chen T, Irby R, et al : Osteopontin identified as lead marker of colon cancer progression using pooled sample expression profiling. J Natl Cancer Inst 94: 513-521, 2002.

8. Rudland PS, Platt-Higgins A, El-Tanani M, et al : Prognostic significance of the metastasis-associated protein osteopontin in human breast cancer. Cancer Res 62: 3417-3427, 2002.

9. Coppola D, Szabo M, Boulware D, Muraca P, Alsarraj M, Chambers AF and Yeatman TJ: Correlation of osteopontin protein expression and pathological stage across a wide variety of tumor histologies. Clin Cancer Res 10: 184-190, 2004.

10. Shang S, Plymoth A, Ge S, Feng Z, Rosen HR, Sangrajrang S, Hainaut P, Marrero JA and Beretta L: Identification of osteopontin as a novel marker for early hepatocellular carcinoma. Hepatology 55: 483-90, 2012.

11. Gong M, Lu Z, Fang G, Bi J and Xue X: A small interfering RNA targeting osteopontin as gastric cancer therapeutics. Cancer Lett 272: 148-159, 2008.

12. Geissinger E, Weisser C, Fischer P, Schartl M and Wellbrock C: Autocrine stimulation by osteopontin contributes to antiapoptotic signalling of melanocytes in dermal collagen. Cancer Res 62: 4820-4828, 2002.

13. Yang G, Zhang Y, Wu J, Xiong J, Deng H, Wang J, Yang C and Zhu Z: Osteopontin regulates growth and migration of human nasopharyngeal cancer cells. Mol Med Rep 4: 1169-1173, 2011.

14. Wong TS, Kwong DL, Sham J, Wei WI, Kwong YL and Yuen AP: Elevation of plasma osteopontin level in patients with undifferentiated nasopharyngeal carcinoma. Eur J Surg Oncol 31: 555-558, 2005.

15. Hui EP, Sung FL, Yu BK, et al: Plasma osteopontin, hypoxia, and response to radiotherapy in nasopharyngeal cancer. Clin Cancer Res 14: 7080-7087, 2008

16. McCain DF, Wu L, Nickel P, Kassack MU, Kreimeyer A, Gagliardi A, Collins DC and Zhang ZY: Suramin derivatives as Inhibitors and activators of protein-tyrosine phosphatases. J Biol Chem 279: 14713-14725, 2004.

17. Chevillard S, Pouillart P, Beldjord C, Asselain B, Beuzeboc P, Magdelenat $\mathrm{H}$ and Vielh P: Sequential assessment of multidrug resistance phenotype and measurement of S-phase fraction as predictive markers of breast cancer response to neoadjuvant chemotherapy. Cancer 77: 292-300, 1996.

18. Kolfschoten GM, Hulscher TM, Pinedo HM and Boven E: Drug resistance features and S-phase fraction as possible determinants for drug response in a panel of human ovarian cancer xenografts. Br J Cancer 83: 921-927, 2000.

19. Zhang G, He B and Weber GF: Growth factor signaling induces metastasis genes in transformed cells: molecular connection between Akt kinase and osteopontin in breast cancer. Mol Cell Biol 23: 6507-6519, 2003.

20. Kim MS, Park MJ, Moon EJ, Kim SJ, Lee CH, Yoo H, Shin SH, Song ES and Lee SH: Hyaluronic acid induces osteopontin via the phosphatidylinositol 3-kinase/Akt pathway to enhance the motility of human glioma cells. Cancer Res 65: 686-691, 2005. 